\title{
Jinekoloji polikliniğine başvuran evli kadınlarda cinsel işlev bozukluğu yaygınlığı ve ilişsili bazı faktörler
}

\section{Prevalence and some related factor of sexual dysfunction among married women admitted to gynecologic outpatient clinic}

\section{Zehra Gölbaşı*, Nilüfer Tuğut, Ayten Şentürk Erenel, Kafiye Eroğlu}

Doğum ve Kadın Hastalıkları Hemşireliği Anabilim Dalı, (Doç. Dr. Z. Gölbaşı, Yrd. Doç. Dr. N. Tuğut), Cumhuriyet Üniversitesi Sağlık Bilimleri Fakültesi TR-58140 Sivas, (Doç. Dr. A. Ş. Erenel) Gazi Üniversitesi Sağlık Bilimleri Fakültesi, TR-06500 Ankara, (Prof. Dr. K. Eroğlu), Koç Üniversitesi Hemşirelik Yüksekokulu, TR-34450 İstanbul

\section{Özet}

Amaç. Bu çalışma bir jinekoloji polikliniğine başvuran kadınlarda cinsel işlev bozukluğu yaygınlığını ve cinsel işlev bozukluğu ile ilişkili bazı faktörleri incelemek amacıyla yapılmıştır. Yöntem. Araştırma bir üniversite hastanesinin jinekoloji polikliniğinde kesitsel olarak yapılmıştır. Örneklem 24 Eylül-4 Aralık 2012 tarihleri arasında çeşitli şikayetler ya da kontrol amacıyla jinekoloji polikliniğine başvuran 216 kadından oluşmuştur. Veriler kadınları tanıtıcı form ve Kadın Cinsel Fonksiyon Indeksi ( Index of Female Sexual Function (IFSF)) ile toplanmıştır. Verilerin istatistiksel analizinde tek yönlü varyans analizi ve ki-kare testi kullanılmıştır. Bulgular. Kadınların IFSF puan ortalaması 25,39 $(\mathrm{SD}=8,67)$ dur ve toplam puana göre (IFSF toplam puan s30) kadınların \%69.4'ü Cinsel İşlev Bozukluğu (CIBB) yaşamaktadır. Jinekolojik şikayetlerle gelen kadınlarda CỉB sıklığı $(\% 78)$, kontrol $(\% 61,5)$ ya da çocuk sahibi olmama $(\% 53,7)$ sorunu nedeniyle gelen kadınlardan daha yüksek bulunmuştur $(\mathrm{p}<0,05)$. Ayrıca, hem kendisi hem de eşi 36 ve üzeri yaş grubunda olan ve 5 yll ve daha az eğitim düzeyine sahip, görücü usulü ile evlenen, evlilik süresi 10 yıldan fazla olan, en az bir kez doğum yapmış olan ve kronik fiziksel bir hastalığı olan kadınlarda CỉB görülme sıklığının daha yüksek olduğu belirlenmiş̧tir $(p<0,05)$. Sonuç. Jinekoloji polikliniğine herhangi bir nedenle başvuran kadınların yarısından fazlası CIBB yaşamaktadır. CİB bozukluğu ileri yaş, eğitim düzeyi (düşük), evlenme şekli (görücü usulü), evlilik süresi (on yıldan fazla), kronik- fiziksel bir hastalığa sahip olma ve jinekolojik sorunlar ile ilişkilidir.

Anahtar sözcükler: Kadın, cinsellik, cinsel işlev bozukluğu

\begin{abstract}
Aim. This study was carried out to examine the prevalence of sexual dysfunction in married women attended to the gynaecologic outpatient clinic and it's correlates. Methods. The study was carried out at gnyecologic outpatient clinic of a university hospital as a cross sectionally. The sapmle of research was consisted of 216 women who admitted to the gynaecological outpatient clinic between September 24th and December 4th 2012 due to various complaints or for control. The data was collected by Individual Characteristic Form and Index of Female Sexual Function (IFSF). One-Way Anova and chi square test were used in the statistical analysis of the data. Results. The IFSF mean score of the women is 25.39 . According to the total IFSF score, $69.4 \%$ of the women has Sexual Dysfunction (SD). The SD prevalance in women who came due to gynaecological complaints (\%78) was found to be higher from women who came for control $(61.5 \%)$ or for infetility $(53.7 \%)$. It was found that the SD prevalence was found to be higher among women who herself and her spouse of 36 years and older age group and educational level of less than 5 years, have been married for more than 10 years and arranged married, have given birth at least once, and have chronic physical disease. Conclusion. More than half of women admitted to the gynecologic outpatient clinic for any reason have SD. Sexual dysfunction was related to advanced age, educational level, type of marriage, years of marriage, chronic-physical disease and gynecological problems.
\end{abstract}

Keywords. Women, sexuality, sexual dysfunction 
Geliş tarihi/Received: 23 Ekim 2013; Kabul tarihi/Accepted: 21 Ocak 2014

\section{*İletişim adresi:}

Dr. Zehra Gölbaşı, Doğum ve Kadın Hastalıkları Hemşireliği Anabilim Dalı, Cumhuriyet Üniversitesi Sağlık Bilimleri Fakültesi, TR-58140 Sivas. E posta: zehragolbasi@gmail.com

*Bu çalışma Kopenhag-Danimarka'da düzenlenen "First Global Conference on Contraception, Reproductive And Sexual Health, 22-25 May 2013” de poster bildiri olarak sunulmuştur.

\section{Giriş}

Bireyin sağlı̆̆ının ve yaşam kalitesinin önemli bir belirleyicisi olan cinsellik insanoğlunun; cinsiyet, toplumsal cinsiyet, cinsel kimlik, cinsel yönelim, erotizm, sevgi ve üreme davranışını kapsayan temel bir boyutudur [1]. Yaşam süreci boyunca birçok faktör cinselliği etkileyerek cinsel sağlık sorunlarının ortaya çıkmasına neden olabilir. Kadın cinselliği açısından bakıldığında gebelik, doğum, menopoz, yaşlılık gibi fizyolojik olayların yanı sıra, infertilite, jinekolojik şikayetler ve jinekolojik kanserler gibi sağlık sorunlarının cinselliği önemli ölçüde etkilediği görülmektedir [1-6]. Tüm bu faktörlerin kompleks etkileşiminin bir sonucu olarak, Cinsel İşlev Bozukluğu (CİB) kadınlarda yaygın olarak ortaya çıkan, yaşa bağımlı, progresif ve kadının genel sağlığının yanı sıra yaşam kalitesini de olumsuz etkileyen bir sağlik sorunudur $[2,3,7,8]$.

CİB, cinsel yanıt döngüsünü oluşturan cinsel istek ve psiko-fizyolojik değişikliklerde azalma ve bozulma sonucu, kişide belirgin sıkıntı veya kişilerarası ilişkilerde zorluk oluşması olarak ifade edilmektedir [3, 9]. CİB görülme sıklığı ülkeden ülkeye, bölgeden bölgeye ve kültürden kültüre değişiklik göstermektedir. West ve ark. [10]'nın belirttiğine göre, kadınlarda CİB ile ilgili yapılan ilk prevelans çalışması 1929 yılında 2200 kadının incelenmesi sonucunda Davis tarafından yayınlanmıştır. CİB'un kadınlarda yaygın bir sağlık problemi olduğu fark edildikten sonra konu ile ilgili çalışmalar giderek artmaya başlamıştır. Farklı ülkelerde yapılmış olan araştırma sonuçları CİB prevelansının \%39$\% 73,3$ arasında değiştiğini göstermektedir [11-18]. Türkiye'de yapılmış olan çalışmalarda ise prevelansın \%28,6-\%68,8 arasında değiştiği görülmektedir [7, 8, 19-23]. Bu sonuçlar Türkiye'de CİB'nun azımsanmayacak boyutta yaşanan ve çözüm bekleyen önemli bir kadın sağlığı sorunu olduğunu göstermektedir.

Yapılan çalışmalar cinsel sorunların kadınların sağlığı ve yaşam kalitesi üzerinde önemli olumsuz etkileri olmasına karşın, birçok kadının yaşadığ 1 cinsel sorun için yardım arama davranışında bulunmadığını göstermektedir [24-27]. Çünkü cinsellik ve cinsel işlevle ilgili sorunlar toplum genelinde çok fazla ifade edilmeyen ve tabu olarak değerlendirilen bir durumdur. Dünyada ve ülkemizde toplumsal cinsiyet temelli eşitsizliklere maruz kalan kadınlar toplumsal baskının da etkisi ile mahrem alan olarak kabul edilen cinsel problemlerini hala açıkça ifade edememektedir [2, 28, 29]. Bu nedenle kadınlar, cinsel sorunların çözümüne yönelik ya hiçbir girişimde bulunmamakta ya da geç yardım arayarak tedavi sürecini uzatmakta ve hastalığın kronikleşmesine neden olabilmektedir. Diğer taraftan cinsel sorunlar sağlık çalışanları tarafından da yeterli bir şekilde ele alınmamakta ve genellikle göz ardı edilmektedir [30]. Bu durum cinsel sorunların daha karmaşık ve çözümü zor bir duruma gelmesine neden olarak, yaşam kalitesi üzerindeki olumsuz etkilerini derinleştirebilmektedir. Oysa sağlık çalışanlarının bireylerle karşılaştıkları çeşitli ortamları, onların cinsel sorunlarını da ifade etmelerine fursat vermek amaciyla kullanabilmeleri önemlidir. Jinekoloji ve obstetri poliklinikleri bu amaçla kullanılabilecek uygun olanlar olabilir. $\mathrm{Bu}$ noktadan hareketle çalışma, jinekoloji polikliniğine başvuran kadınlarda cinsel işlev bozukluğu yaygınlığını ve cinsel işlev bozukluğu ile ilişkili bazı faktörleri incelemek amacıyla yapılmıştır. Böylece konunun önemine dikkat çekilecek, mevcut durum saptanarak uygun tedavi ve yaklaşımların geliştirilmesine katkıda bulunulacaktır. 


\section{Gereç ve yöntem}

Kesitsel türde olan araştırma bir üniversite hastanesinin jinekoloji polikliniğine başvuran kadınlarda CİB yaygınlığını ve CİB ile ilişkili bazı faktörleri incelemek amacıyla 24 Eylül-4 Aralık 2012 tarihleri arasında yapılmıştır. Örnekleme alınma kriterleri; 18 yaş üzeri, evli, menopoza girmemiş olma ve gebe olmama olarak belirlenmiştir. Araştırmanın örneklemini belirlenen tarihler arasında çeşitli şikayetler ya da kontrol için polikliniğe başvuran ve kriterlere uyan 240 kadın oluşturmuştur. Ancak 24 kadın çalışmaya katılmayı kabul etmediği için örneklem 216 kadından (Katılım oranı \%90) oluşmuştur.

Veriler, kadınların bireysel ve jinekoloji polikliniğine gelme nedenleri ile ilgili bazı özeliklerini belirlemek amacıyla oluşturulan Tanıtıcı Özellikler Formu ve Kadın Cinsel Fonksiyon İndeksi (Index of Female Sexual Function (IFSF)) ile toplanmıştır. Tanıtıcı özelikler formu araştırmacılar tarafından geliştirilmiş̧tir. Formda kadınların yaş, öğrenim düzeyi, çalışma durumu, eşin yaşı, aile tipi, gelir durumu, yaşadığı yer, evlilik yaşı, evlilik süresi, gebelik, doğum ve çocuk sayısı, jinekoloji polikliniğine başvurma nedeni, jinekolojik şikayet olma durumu, şikayetlerin ne kadar zamandır devam ettiğini belirlemeye yönelik sorular yer almaktadır.

IFSF Kaplan ve ark. [31] tarafından kadın cinsel fonksiyonu ile ilgili yönleri (lubrikasyon, orgazmik fonksiyon, cinsel istek, ilişki tatmini, klitoral duyarlılık ve genel tatmin) değerlendirmek için geliştirilmiştir. Yılmaz ve Eryılmaz [32] tarafından Türk toplumuna uyarlanmış ve Cronbach Alfa katsayısı 0.82 olarak bulunmuştur. Ölçek kadının son bir aylık dönemdeki cinsel fonksiyonunu sorgulamaktadır. Yanıtların derecelendirilmesi 1 (neredeyse hiç ya da hiç) ve 5 (hemen hemen her zaman ya da her zaman) arasındadır. Son bir ay içinde cinsel ilişkide bulunmayanlara 0 puan verilmektedir. Ölçeğin her bir maddesine ait puanlar toplanarak toplam puan elde edilir. Ölçekten alınabilecek en yüksek puan 49'dur. IFSF toplam puanın $\leq 30$ olduğu durumda Cinsel İşlev Bozukluğu (CİB)'nun olduğu kabul edilmektedir. Alt başlıkların puanlaması işe şöyledir. Cinsel ilişki kalitesi (soru 1ve 2); 0-10 puan, lubrikasyon (soru 2); 0-5 puan, cinsel istek (soru 4-5); 2-10 puan, cinsel ilişki tatmini (soru 6-7); 2-10 puan, orgazmik fonksiyon (soru 8); 1-5 puan ve klitoral duyarlılık (soru 9); 1-5 puan. Çalışmamızda ölçeğin Cronbach Alfa katsayısı 0.89 olarak bulunmuştur.

Bu çalışma Helsinki Deklarasyonu'na uygun olarak yürütülmüştür. Çalışmanın yapılacağ 1 kurumdan yazılı, kadınlardan sözlü onam alınmıştır. Araştırmaya katılma gönüllülük esasına dayanmıştır ve kadınların kimlik bilgileri alınmamıştır. Araştırmanın verileri formlar aracılığıyla poliklinikte uygun bir odada okur yazar olan kadınların bireysel doldurmaları sağlanarak, okuryazar olmayan kadınlarla (14 kadın) ise yüz yüze görüşülerek toplanmıştır. Veriler bilgisayarda SPSS (14.0) programında analiz edilmiştir. Nominal veriler frekans dağılımı olarak, ordinal veriler ortalama ve standart sapma şeklinde sunulmuştur. Verilerin istatistiksel analizinde tek yönlü varyans analizi ve kikare testi kullanılmıştır.

\section{Bulgular}

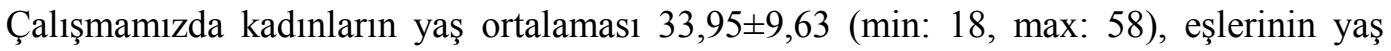

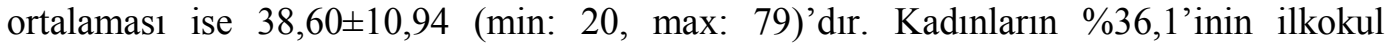
mezunu, eşlerinin ise \%35,2'sinin lise mezunu olduğu saptanmıştır. Kadınların evlenme

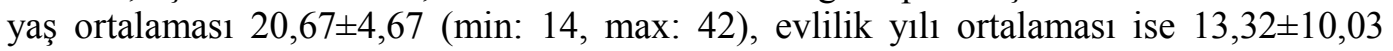
(min: 1, max: 42) dir. Kadınların gebelik ve doğum sayısı ortalamasına bakıldığında ise

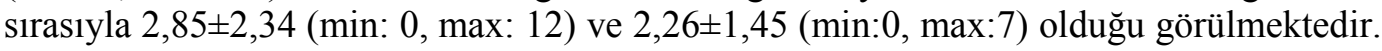
Kadınların \%32,5'inin en az bir kez spontan obortus, \%39'unun kürtaj öyküsü vardır. Kadınların \%22,2'sinin tanısı konmuş kronik bir fiziksel hastalığ 1 , \%12,0'ının ise herhangi bir ruhsal hastalığ mevcuttur. 
Tablo 1. Kadınların IFSF toplam ve alt boyut puan ortalaması.

\begin{tabular}{lll}
\hline IFSF toplam ve alt boyutları & Ortalama (SD) & Alınabilecek maksimum puan \\
\hline Cinsel ilişki kalitesi & $6,54(3,21)$ & 10 \\
Lubrikasyon & $3,33(1,74)$ & 5 \\
Cinsel istek & $5,30(1,92)$ & 10 \\
Cinsel ilişki tatmini & $6,20(2,36)$ & 10 \\
Orgazmik fonksiyon & $2,63(1,25)$ & 5 \\
Klitoral duyarlilık & $2,46(0,95)$ & 5 \\
Toplam IFSF & $25,39(8,67)$ & 49 \\
\hline
\end{tabular}

Tablo 1'de kadınların IFSF toplam puan ortalamasının 25,39 $(\mathrm{SD}=8,67)$ olduğu görülmektedir. Ölçekten elde edilen toplam puana göre kadınların \%69,4'ünün CİB sorunu yaşadıkları (IFSF $\leq 30$ ) bulunmuştur.

Tablo 2. Kadınların bazı sosyodemografik özelliklerine göre CİB yaşama durumlarının dağılımı.

\begin{tabular}{|c|c|c|c|c|c|}
\hline \multirow{3}{*}{ Özellikler } & \multicolumn{4}{|c|}{ Cinsel işlev bozukluğu } & \multirow{3}{*}{$\mathbf{x}^{2} / \mathbf{p}$} \\
\hline & \multicolumn{2}{|c|}{ Var (IFSF $\leq 30)$ n:150 } & \multicolumn{2}{|c|}{ Yok (IFSF >30) n:66 } & \\
\hline & n & $(\%)$ & $\mathbf{n}$ & $(\%)$ & \\
\hline \multicolumn{6}{|l|}{ Yaş } \\
\hline $18-35$ & 77 & $(60,6)$ & 73 & $(82,0)$ & \multirow[t]{2}{*}{$11,28 / 0,001$} \\
\hline 36 ve üzeri & 50 & $(39,4)$ & 16 & $(18,0)$ & \\
\hline \multicolumn{6}{|l|}{ Eğitim yılı } \\
\hline 5 yil ve daha az & 83 & $(83,0)$ & 17 & $(17,0)$ & \multirow[t]{2}{*}{$16,12 / 0,001$} \\
\hline 6 yıl ve üzeri & 67 & $(57,8)$ & 49 & $(42,2)$ & \\
\hline \multicolumn{6}{|c|}{ Çalıșma durumu } \\
\hline Çalışıyor & 28 & $(71,8)$ & 11 & $(28,2)$ & \multirow[t]{2}{*}{$0,12 / 0,443$} \\
\hline Çalışmiyor & 122 & $(68,9)$ & 55 & $(31,1)$ & \\
\hline \multicolumn{6}{|l|}{ Eşin yaşı } \\
\hline $20-35$ & 57 & $(57,0)$ & 43 & $(43,0)$ & \multirow[t]{2}{*}{$13,59 / 0,001$} \\
\hline 36 ve üzeri & 93 & $(80,2)$ & 23 & $(19,8)$ & \\
\hline \multicolumn{6}{|c|}{ Eşin eğitim yılı } \\
\hline 5 yil ve daha az & 59 & $(78,7)$ & 16 & $(21,3)$ & \multirow[t]{2}{*}{$4,60 / 0,032$} \\
\hline 6 yıl ve üzeri & 91 & $(64,5)$ & 50 & $(35,5)$ & \\
\hline \multicolumn{6}{|l|}{ Aile tipi } \\
\hline Çekirdek & 111 & $(71,2)$ & 45 & $(28,8)$ & \multirow[t]{2}{*}{$0,77 / 0,379$} \\
\hline Geniş & 39 & $(65,0)$ & 21 & $(35,0)$ & \\
\hline \multicolumn{6}{|l|}{ Gelir durumu } \\
\hline Düşük & 35 & $(83,3)$ & 7 & $(16,7)$ & \multirow[t]{3}{*}{$5,19 / 0,074$} \\
\hline Orta & 98 & $(67,1)$ & 48 & $(32,9)$ & \\
\hline İyi & 17 & $(60,7)$ & 11 & $(39,3)$ & \\
\hline \multicolumn{6}{|l|}{ Yaşadığı yer } \\
\hline İl & 81 & $(67,5)$ & 39 & $(32,5)$ & \multirow[t]{3}{*}{$0,48 / 0,785$} \\
\hline İlçe & 43 & $(71,7)$ & 17 & $(28,3)$ & \\
\hline Köy-kasaba & 26 & $(72,2)$ & 10 & $(27,8)$ & \\
\hline
\end{tabular}

Tablo 2'de hem kendisi hem de eşi 36 ve üzeri yaş grubunda olan ve 5 yıl ve daha az eğitime sahip kadınlarda cinsel işlev bozukluğu görülme sıklığının istatistiksel olarak anlamlı düzeyde yüksek olduğu görülmektedir $(\mathrm{p}<0,05)$. Kadınların çalışma durumu, gelir durumu, aile tipi ve yaşadıkları yere göre cinsel işlev bozukluğu yaşama durumları arasında ise istatistiksel olarak anlamlı bir fark olmadığı bulunmuştur $(\mathrm{p}>0,05)$. 
Tablo 3. Kadınların evlilik, doğurganlık ve genel sağlık özelliklerine göre CİB yaşama durumlarının dağılımı.

\begin{tabular}{|c|c|c|c|}
\hline \multirow{2}{*}{ Özellikler } & \multicolumn{2}{|c|}{ Cinsel işlev bozukluğu } & \multirow{2}{*}{$\mathbf{x}^{2} / \mathbf{p}$} \\
\hline & Var (IFSF $\leq 30)$ n:150 & Yok $($ IFSF >30) n:66 & \\
\hline \multicolumn{4}{|l|}{ Evlilik yaşı } \\
\hline 19 yaş ve altı & $70(68,6)$ & $32(31,4)$ & \multirow[t]{2}{*}{$0,06 / 0,460$} \\
\hline 20 ve üzeri & $80(70,2)$ & $34(29,8)$ & \\
\hline \multicolumn{4}{|c|}{ Evlenme şekli } \\
\hline Görücü & $109(73,6)$ & $39(26,4)$ & \multirow[t]{2}{*}{$3,91 / 0,035$} \\
\hline Anlaşarak & $41(60,3)$ & $27(39,7)$ & \\
\hline \multicolumn{4}{|l|}{ Evlilik süresi } \\
\hline 10 y1l ve altı & $61(57,5)$ & $45(42,5)$ & \multirow[t]{2}{*}{$18,88 / 0,001$} \\
\hline 11 yıl ve üzeri & $89(80,9)$ & $21(19,1)$ & \\
\hline \multicolumn{4}{|c|}{ Gebelik sayısı } \\
\hline 0 & $27(61,4)$ & $17(38,6)$ & \multirow[t]{2}{*}{$1,70 / 0,192$} \\
\hline 1 ve üzeri & $123(71,5)$ & $49(28,5)$ & \\
\hline \multicolumn{4}{|c|}{ Doğum sayısı } \\
\hline 0 & $8(47,1)$ & $9(52,9)$ & \multirow[t]{2}{*}{$5,53 / 0,019$} \\
\hline 1 ve üzeri & $115(74,2)$ & $40(25,8)$ & \\
\hline \multicolumn{4}{|l|}{ Düşük } \\
\hline Yok & $90(79,6)$ & $23(20,4)$ & \multirow[t]{2}{*}{$1,59 / 0,207$} \\
\hline Var & $17(68,0)$ & $8(32,0)$ & \\
\hline \multicolumn{4}{|l|}{ Kürtaj } \\
\hline Var & $74(70,5)$ & $31(29,5)$ & \multirow[t]{2}{*}{$1,25 / 0,264$} \\
\hline Yok & $25(80,6)$ & $6(19,4)$ & \\
\hline \multicolumn{4}{|c|}{ Ruhsal hastalık } \\
\hline Evet & $21(80,8)$ & $5(19,2)$ & \multirow[t]{2}{*}{$1,78 / 0,132$} \\
\hline Hayir & $129(67,9)$ & $61(32,1)$ & \\
\hline \multicolumn{4}{|c|}{ Fiziksel kronik hastalık } \\
\hline Evet & $40(83,3)$ & $8(16,7)$ & \multirow[t]{2}{*}{$5,61 / 0,012$} \\
\hline Hayır & $110(65,5)$ & $58(34,5)$ & \\
\hline
\end{tabular}

Tablo 3'te görücü usulü ile evlenen, evlilik yılı on yıldan fazla olan, en az bir kez doğum yapan ve kronik fiziksel bir hastalığı olan kadınlarda CỈB görülme sıklığının istatistiksel olarak anlamlı düzeyde yüksek olduğu belirlenmiştir $(p<0,05)$. Kadınların evlilik yaşı, gebelik sayısı, düşük ve kürtaj yaşama durumu ve kronik ruhsal bir hastalığa sahip olma özelliklerine göre CIBB yaşama durumları arasında istatistiksel olarak anlamlı bir fark olmadığı saptanmıştır ( $\mathrm{p}>0,05)$.

Tablo 4. Kadınların jinekoloji polikliniğine geliş nedeni ve jinekolojik şikayetlerinin süresine göre CİB yaşama durumlarının dağılımı.

\begin{tabular}{|c|c|c|c|}
\hline \multirow{2}{*}{ Değişkenler } & \multicolumn{2}{|c|}{ Cinsel işlev bozukluğu } & \multirow{2}{*}{$\mathbf{x}^{2} / \mathbf{p}$} \\
\hline & $\operatorname{Var}($ IFSF $\leq 30)$ & Yok $($ IFSF >30) & \\
\hline \multicolumn{4}{|c|}{ Jinekoloji polikliniğine geliş nedeni (216) } \\
\hline Jinekolojik şikayet & $96(78,0)$ & $27(22,0)$ & $10,63 / 0,005$ \\
\hline Kontrol & $32(61,5)$ & $20(38,5)$ & \\
\hline Çocuk sahibi olamama & $22(53,7)$ & $19(46,3)$ & \\
\hline \multicolumn{4}{|c|}{ Jinekolojik şikayetin süresi $(n=123)$} \\
\hline 30 gün ve daha az & $58(82,9)$ & $12(17,1)$ & $2,19 / 0,139$ \\
\hline 31 günden fazla & $38(71,7)$ & $15(28,3)$ & \\
\hline
\end{tabular}

Tablo 4'te kadınların jinekoloji polikliniğine başvuru nedenine göre CİB yaşama durumları arasında istatistiksel olarak anlamlı bir fark olduğu $(\mathrm{p}<0,05)$, jinekolojik şikayetlerle başvuran kadınlarda CİB görülme sıklığının (\%78), rutin sağlık kontrolü $(\% 61,5)$ ve çocuk sahibi olamama $(\% 53,7)$ nedeniyle başvuran kadınlardan daha yüksek olduğu saptanmıştır. Kadınların jinekolojik şikayetlerinin süresine göre CỉB yaşama durumları arasında anlamlı bir fark olmadığı belirlenmiştir $(\mathrm{p}>0,05)$. 


\section{Tartışma}

Çalışmamızda kadınların IFSF toplam puan ortalamasının 25,39 ( $\mathrm{SD}=8,67)$ olduğu, ve ölçeğin kesme noktası dikkate alındığına yaklaşık 3/2'sinde $(\% 69,4)$ CỉB olduğu belirlenmiştir (Tablo 1). Ülkemizde jinekoloji polikliniğine başvuran 18-56 yaş arası 425 kadın üzerinde yapılan başka bir çalışmada ise CIBB prevelansı \%52,2 bulunmuş olup [8], bu sonuç bizim sonucumuzdan düşüktür. Kadınlarda CİB, ağırlıklı olarak sağlıklı kadınlarda ya da herhangi bir nedenle sağlık kurumuna başvuranlarda yapılmış olup, sonuçlar değişkendir. Bu durum çalışmanın yapıldığı toplum ve kültürel farklılıklardan kaynaklanabileceği gibi, kadınların CİB dışındaki diğer sağlık sorunları ve bireysel özelliklerinin farklı olmasından da kaynaklanabilir. Nitekim yine ülkemizde 15-49 yaş arasında 188 sağlıklı kadın üzerinde yapılmış bir başka çalışmada CỉB yaygınlığı \%45,6 olarak saptanmıştır [7]. Amerika'da yapılmış olan Ulusal Sağlık ve Sosyal Yaşam Çalışması'na (National Health and Social Life Survey -NHSLS) göre, 18 ve 59 yaş arası 1.749 kadının \%43'ünde bir veya daha fazla cinsel şikayet bulunduğu saptanmıştır [11]. İngiltere'de yapılan bir çalışmada kadınların \%54'ünün son bir yılda en az bir cinsel problem yaşadıkları ve bu nedenle \%62'sinin cinsel ilişkiden kaçındı ğı, problem yaşayan kadınların yalnız \%21'inin yardım talep ettiği belirlenmiştir [13]. Kanada'da ulusal düzeyde 18-44 yaş grubunda yapılmış bir çalışmada kadınların \%39'unda [12], Brazilya'da 18 yaş üzeri kadınların \%49'unda [14], Kuveyt'te 16-49 yaş kadınların \%69'unda [15], Yunanistan'da 18-72 yaş arası kadınların \%48'inde [16], Hindistan'da 17-75 yaş arası kadınların \%73,3'ünde [17], 11 Latin Amerika ülkesinde 40-59 yaş cinsel yönden aktif 5391 kadının \%56,8'inde [33] CIBB saptanmıştır. Görüldüğü gibi hem Türkiye'de hem de dünyanın bir çok ülkesinde yapılan çalışmalarda CİB prevelansı kadınların yarısından fazlasında görülen ve çözüm bekleyen önemli bir sağlık sorunu olarak karşımıza çıkmaktadır. Çalışma sonucumuz bazı çalışmalara göre yüksek, bazı çalışma sonuçlarıyla da benzerlik göstermektedir. $\mathrm{Bu}$ sonuçlarda, kadınların içinde yaşadıkları toplumun refah düzeyi ve kadının statüsünün etkisi olabilir. Ülkelerin gelişmişlik düzeyi artıkça kadının statüsü artmakta, statü artıkça kadının kendi bedeni ile ilgili sağlıklı kararlar vermesi nedeniyle CiB görülme sıklı̆̆ı değişebilmektedir.

Yaşam kalitesinin önemli bir bileşeni olan kadının cinsel işlevi; fizyolojik, psikolojik ve sosyokültürel pek çok faktörlerden etkilenmektedir. Kadının cinsel fonksiyonunda genetik yatkınlık dahil çok sayıda biyolojik, bilişsel, emosyonel ve sosyal faktörler rol oynamaktadır [4, 5, 34-36]. Özellikle doğurganlık ve yaşla birlikte kadın cinsel fonksiyonda önemli değişikler yaşanmaktadır [19, 20, 22, 23, 26, 37]. Çalışmamızda da kadının ve eşinin yaşı (36 yaş üzeri) ve kadının eğitim süresi ( 5 yıldan az) ile CỉB yaşama arasında anlamlı ilişki saptanmıştır (Tablo 2). Singh ve ark. [17] Hindistan'da yaptıkları çalışmada benzer şekilde 40 yaş üzeri ve eğitim düzeyi düşük kadınlarda CİB yaşama oranını daha yüksek bulmuşlardır. Başka bir çalışmada da 48 yaş üzeri olma ile CiB yaşama arasında bir ilişki varlığı gösterilmiştir [33]. Ülkemizde yapılan çalışmalarda da yaşla birlikte CİB prevalansının giderek arttığı dikkati çekmektedir [19, 20, 22, 23]. Çalışmamız bu sonuçları destekler özellikte olup, yaşın ilerlemesi ve doğurganlık süreci ile kadının üreme organlarında meydana gelen fizyolojik değişikliklerin cinsel yaşamı etkilemesinin beklenen bir durum olduğu söylenebilir. Eğitim düzeyi kadının statüsünün önemli belirleyicisidir. Eğitim düzeyinin yükselmesi ile kadının kendi sağlığı ve sağlık bakımı üzerinde daha fazla söz sahibi olması, onun cinsel yaşamını da olumlu etkilenebileceği düşünülmektedir. Çalışmamızda olduğu gibi yapılan bazı çalışmalarda da eğitim düzeyi düşük kadınların eğitim düzeyi yüksek olanlara göre daha fazla CİB yaşadığı bulunmuştur $[7,8,17,23,38-40]$. Çalışmamızda eğitim düzeyi düşük olan kadınlarda olduğu gibi eşin eğitim düzeyinin de CİB'nu etkilediği ve eşinin eğitim düzeyi düşük olan kadınlarda CİB yaşama sıklığının daha yüksek olduğu bulunmuş $(p<0.05)$ olup, bu sonuç da diğer bazı araştırmalar tarafından desteklenmektedir [7, 23, 38, 40]. 
Çalışmamızda diğer çalışmalardan $[8,23]$ farklı olarak kadınların çalışma durumu, gelir durumu, aile tipi ve yaşadıkları yere göre CIBB yaşama durumları arasına istatistiksel olarak anlamlı bir fark bulunmamıştır ( $>0,05)$ (Tablo 2). Bu durum örneklemde yer alan bireylerin farklı olan diğer özelliklerinden kaynaklanıyor olabilir.

Doğurganlık süreci üreme organlarında kalıcı ve geçici bazı değişiklere neden olmaktadır. Yaşanan bu değişikler; sık, çok, erken ve ileri yaş gebelikler, zor doğum, müdahaleli doğumlar gibi bazı özel durumlar üreme organlarında hasar yapma riski nedeniyle cinsel yaşamı etkileyebilmektedir $[1,4,5]$. Çalışmamızda evlenme şekli, doğum sayısı ile CỉB yaşama durumu arasındaki fark önemli $(\mathrm{p}<0,05)$ bulunmuştur (Tablo 3 ). Doğurganlığın CIBB ile ilişkisini belirlemek amacıyla yapılan çalışmalarda farklı sonuçlar dikkati çekmektedir. Sonuçlarımızı destekler nitelikte çalışmaların çoğunda aşırı doğurganlık CİB açısından bir risk faktörü olarak saptanırken [8, 23, 36, 37, 39, 41], bazı çalışmalarda doğurganlık ile CIBB arasında bir ilişki bulunmamıştır [8, 42]. Bu sonuçların farklılığında çalışmanın yapıldığı örneklemin sosyokültürel özelliklerinin etkisi olabilir. Görücü usulü ile evlenen kadınlarda CİB'nun daha sık görülmesi ise, bu kadınların genellikle eğitim düzeyleri ve sosyal statülerinin düşük olma olasılıkları ile açıklanabilir.

Çalışmamızda ruhsal hastalığa sahip olma ile CİB yaşama durumu arasında fark önemsiz bulunurken $(\mathrm{p}>0,05)$, fiziksel kronik bir hastalığa sahip olma ile CİB yaşama durumu arasındaki fark önemli $(\mathrm{p}<0,05)$ bulunmuştur (Tablo3). Özerdoğan [23]'ın çalışması da bizim sonucumuzu desteklemektedir. Bu sonuçta, kronik hastalık nedeniyle kullanılan ilaçların cinsel fonksiyon üzerindeki etkisinin rolü düşünülebileceği gibi, kronik hastalıkların genellikle ilerleyen yaşlarda ortaya çıkan bir durum olduğu ve bizim çalışmamızda da yaşla beraber CİB artmasının bu durumu destekleyen bir bulgu olarak ele alınabileceği söylenebilir.

Kadınlar farklı sorunlarla jinekoloji polikliniğine başvurmaktadır. Çalışmamızda kadınların jinekoloji polikliniğe geliş nedeni ile CiBB yaşama durumu arasında fark önemli $(p<0,05)$ bulunurken, jinekolojik şikayetlerin süresi ile CIB yaşama durumu arasındaki fark önemsiz ( $>0,05)$ bulunmuştur (Tablo 4). CİB sıklığı jinekolojik şikayetlerle başvuran kadınlarda, kontrol ya da çocuk sahibi olamadığı için başvuran kadınlardan daha yüksektir. Kontrol amaçlı ya da çocuk sahibi olamama nedeniyle başvuran kadınların jinekolojik şikayeti olan kadınlara göre daha az CİB yaşaması beklenen bir sonuç olarak düşünülebilir. Özerdoğan ve ark. [23]'nın çalışmasında da üriner, genital enfeksiyon ve inkontinans sorunu yaşama durumuna göre CİB arasındaki fark önemli bulunmuştur. Benzer şekilde Erbil [8]'in çalışmasında da genital enfeksiyon ya da semptomu olan kadınlarda cinsel disfonksiyon oranı daha yüksek belirlenmiştir.

Sonuç olarak; çalışmamızda jinekoloji polikliniğine herhangi bir nedenle başvuran kadınların hemen hemen yarısından fazlasının CỉB yaşadığı ve bu sorunun ileri yaş, eğitim düzeyi (düşük), evlenme şekli (görücü usulü), evlilik süresi (on yıldan fazla), doğurganlık (en az bir doğum yapma) ve kronik fiziksel bir hastalığa sahip olma ile ilişkili olduğu bulunmuştur. Bu sonuca dayanarak sağlık çalışanlarının CỉB konusunda eğitilmeleri ve çiftlere soruna yönelik danışmanlık yapmaları, konuya yönelik daha geniş çaplı erkekleri de kapsayan araştırmaların planlanması, yazılı-görsel eğitim materyallerinin geliştirilmesi önerilir.

\section{Kaynaklar}

1. Fogel CI, Woods NF. Women's Sexuality. Women's Health Care in Advanced Practice Nursing, 1nd ed. New York: Springer Publishing Company 2008; pp: 295-1

2. İncesu C. Cinsel işlevler ve cinsel işlev bozuklukları. Klinik Psikiyatri 2004; 3: 313.

3. Srivastava R, Thakar R, Sultan A. Female sexual dysfunction in obstetrics and gynecology. Obstet Gynecol Surv 2008; 63: 527-37. 
4. Mete S. Kadın ve Cinsellik. Şirin A, Kavlak O, editör. Kadın Sağlığı. 1. Baskı. İstanbul: Bedray Basın Yayıncılık Ltd. Şti. 2008; pp: 110-23.

5. Demirci N. Kadının Yaşam Dönemlerinde Cinsellik ve Cinsel Sağlık. Coşkun A, editör. Kadın Sağlığı ve Hastalıkları El Kitabı. 2. Baskı. İstanbul: Koç Üniversitesi Yayınlar1; 2012; pp: 540-78.

6. Hacivelioğlu S, Alan C, Koçoğlu H, Alan H, Ersay AR. Stres üriner inkontinansın kadın cinsel fonksiyonları üzerindeki etkisi. Türkiye Klinikleri J Gynecol Obst 2012; 22: 71-7.

7. Ege E, Akın B, Yaralı Arslan S, Bilgili N. Sağlıklı kadınlarda cinsel fonksiyon bozukluğu sıklığı ve risk faktörleri. TÜBAV Bilim Dergisi 2010; 3: 137-44.

8. Erbil N. Prevalence and risk factors for female sexual dysfunction among Turkish women attending a maternity and gynecology outpatient clinic. Sex Disabil 2011; 29: 377-86.

9. Marthol H, Hilz MJ. Female sexual dysfunction: A systematic overview of classification, pathophysiology, diagnosis and treatment. Fortschr Neurol Psychiatr 2004; 72: 121-35.

10. West SL, D'Aloisio AA, Agans RP, Kalsbeek WD, Borisov NN, Thorp JM. Prevalence of low sexual desire and hypoactive sexual desire disorder in a nationally representative sample of US women. Arch Intern Med 2008; 168: 1441-9.

11. Laumann EO, Paik A, Rosen RC. Sexual dysfunction in the United States: Prevalence and predictors. JAMA 1999; 281: 537-44.

12. Fisher WA, Boroditsky R, Bridges M. Canadian contraception study 1998. Can J Hum Sex 1999; 8: 161-220.

13. Mercer CH, Fenton KA, Johnson AM, Wellings K, Macdowall W, McManus S, Nanchahal K, Erens B. Sexual function problems and help seeking behaviour in Britain: national probability sample survey. BMJ 2003; 327: 426-7.

14. Abdo CH, Oliveira WM Jr, Moreira ED Jr, Fittipaldi JA. Prevalence of sexual dysfunctions and correlated conditions in a sample of Brazilian women--results of the Brazilian study on sexual behavior (BSSB). Int J Impot Res 2004; 16: 1606.

15. Elnashar AM, El-Dien Ibrahim M, El-Desoky MM, Ali OM, El-Sayd Mohamed Hassan M. Female sexual dysfunction in Lower Egypt. BJOG 2007; 114: 201-6.

16. Ferenidou F, Kapoteli V, Moisidis K, Koutsogiannis I, Giakoumelos A, Hatzichristou D. Presence of a sexual problem may not affect women's satisfaction from their sexual function. J Sex Med 2008; 5: 631-9.

17. Singh JC, Tharyan P, Kekre NS, Singh G, Gopalakrishnan G. Prevalence and risk factors for female sexual dysfunction in women attending a medical clinic in South India. J Postgrad Med 2009; 55: 113-20.

18. Hullfish KL, Pastore LM, Mormon AJ, Wernecke Y, Bovbjerg VE, Clayton AH. Sexual functioning of latino women seeking outpatient gynecologic care. J Sex Med 2009; 6: 61-9.

19. Çayan S, Akbay E, Bozlu M, Canpolat B, Acar D, Ulusoy E. The prevalence of female sexual dysfunction and potential risk factors that may impair sexual function in Turkish women. Urol Int 2004; 72: 52-7.

20. Öksüz E, Malhan S. Prevalence and risk factors for female sexual dysfunction in Turkish Women. Journal Urol 2006; 175: 654-8.

21. Demir Ö, Parlakay N, Gök G, Esen AA. Hastane çalışanı bayanlarda cinsel işlev bozukluğu. Türk Üroloji Dergisi 2007; 33: 156-60.

22. Aslan E, Beji NK, Gungor I, Kadioglu A, Dikencik BK. Prevalence and risk factors for low sexual function in women: A study of 1,009 women in an outpatient clinic of a university hospital in Istanbul. J Sex Med 2008; 5: 2044-52.

23. Özerdoğan N, Sayıner FD, Köşgeroğlu N, Ünsal A. 40-65 yaş grubu kadınlarda cinsel fonksiyon bozukluğu prevelans1, depresyon ve diğer ilişkili faktörler. Maltepe Üniversitesi Hemşirelik Bilim ve Sanatı Derg 2009; 2: 46-58. 
24. Buvat J, Glasser D, Neves RC, Duarte FG, Gingell C, Moreira ED Jr; Global Study of Sexual Attitudes and Behaviours (GSSAB) Investigators' Group. Sexual problems and associated help-seeking behavior patterns: Results of a populationbased survey in France. Int J Urol 2009; 16: 632-8.

25. Vahdaninia M, Montazeri A, Goshtasebi A. Help-seeking behaviors for female sexual dysfunction: A cross sectional study from Iran. BMC Women's Health 2009; 9:3.

26. Moreira ED Jr, Brock G, Glasser DB, Nicolosi A, Laumann EO, Paik A, Wang T, Gingell C; GSSAB Investigators' Group. Help-seeking behaviour for sexual problems: The global study of sexual attitudes and behaviors. Int J Clin Pract 2005; 59: 6-16.

27. Bagherzadeh R, Zahmatkeshan N, Gharibi T, Akaberian S, Mirzaei K, Kamali F Pouladi S, Yazdanpanah S, Jamand T, Yazdankhahfard M, Khoramroudi R. Prevalence of female sexual dysfunction and related factors for under treatment in Bushehrian Women of Iran. Sex Disabil 2010; 28: 39-49.

28. Türkiye İstatistik Kurumu. Kadın İstatistikleri 2012; Ankara.

29. WHO. Women and Health. Geneva: WHO Press 2009; pp: 9-11.

30. Dahir M. A sexual medicine health care model and nurse practitioner role. Urol Nurs 2011; 31: 359-62.

31. Kaplan SA, Reis RB, Kohn IJ, Ikequchi EF, Laor E, Te AE, Martins AC. Safety and efficacy of sildenafil in postmenopausal women with sexual dysfunction. Urology 1999; 53: 481-6.

32. Y1lmaz CA, Eryılmaz HY. Kadın Cinsel Fonksiyon Sorgulama İndeksinin (IFSF) geçerlik- güvenilirlik çalışması. Androloji Bülteni 2004; 18: 275-6.

33. Blümel JE, Chedraui P, Baron G, Belzares E, Bencosme A, Calle A, Espinoza MT, Flores D, Izaguirre $\mathrm{H}$, Leon-Leon $\mathrm{P}$, Lima S, Mezones-Holguin E, Monterrosa A, Mostajo D, Navarro D, Ojeda E, Onatra W, Royer M, Soto E, Vallejo S, Tserotas K; Collaborative Group for Research of the Climacteric in Latin America (REDLINC). Sexual dysfunction in middle-aged women: A multicenter Latin American study using the Female Sexual Function Index. Menopause 2009; 16: 1139-48.

34. Eshghi R, Bahrami F, Fatehi Zade M, Etemadi O, Ghasemi V. The prediction of sexual function based on cognitive-Emotional factors in Iranian Women. Interdisciplinary JCRB 2012; 4: 53-60.

35. Brotto LA, Chik HM, Ryder AG, Gorzalka BB, Seal BN. Acculturation and sexual function in Asian Women. Arch Sex Behav 2005; 34: 613-26.

36. Mert DG, Erberk Özen N. Genel psikiyatri polikliniğine başvuran kadın hastalarda cinsel işlev bozukluğu ve ilişkili sosyokültürel parametrelerin değerlendirilmesi. Klinik Psikiyatri 2011; 14: 85-93.

37. Sidi H, Puteh SE, Abdullah N, Midin M. The prevalence of sexual dysfunction and potential risk factors that may impair sexual function in Malaysian Women. J Sex Med 2007; 4:311-21.

38. Chedraui P, Pérez-López FR, Sánchez H, Aguirre W, Martínez N, Miranda O, Plaza MS, Schwager G, Narváez J, Quintero JC, Zambrano B. Assessment of sexual function of mid-aged Ecuadorian women with the 6-item Female Sexual Function Index. Maturitas 2012; 71: 407-12.

39. Chedraui P, Pérez-López FR, Mezones-Holguin E, San Miguel G, Avila C; Collaborative Group for Research of the Climacteric in Latin America (REDLINC). Assessing predictors of sexual function in mid-aged sexually active women. Maturitas 2011; 68: 387-90.

40. Llaneza P, Fernández-Iñarrea JM, Arnott B, García-Portilla MP, Chedraui P, Pérez-López FR. Sexual function assessment in postmenopausal women with the 14-item changes in sexual functioning questionnaire. J Sex Med 2011; 8: 214451. 
41. Erenel AŞ, Kıtış Y. Kadın cinsel fonksiyonunun belirlenmesine yönelik bir çalışma. Turkiye Klinikleri J Gynecol Obst 2011; 21: 251-9.

42. Güvel S, Yaycıoğlu Ö, Bağış T, Savaş N, Bulgan E, Özkardeş H. Evli kadınlarda cinsel fonksiyonlara etkin faktörler. Türk Üroloji Dergisi 2003; 29: 43-8. 